\title{
Application of Value Chain Management to Longan Industry
}

\author{
Apichat Sopadang, \\ Korrakot Y. Tippayawong and Woramol Chaowarut
}

Department of Industrial Engineering,

Faculty of Engineering, Chiang Mai University, Chiang Mai, 50200, Thailand

Received 2012-03-27, Revised 2012-07-25; Accepted 2012-07-25

\begin{abstract}
Longan plays an important role as an economic fruit of Thailand because of its volume and size in markets, both domestic and aboard. It was generally known that serious problems were encountered in current longan production and sale, especially the increased production cost. To understand the overall situation clearly, longan's supply chain was evaluated using the Supply Chain Operations Reference (SCOR) model and value chain analysis. In-depth interviews were conducted with 73 supply chain members, covering farmers, middlemen, process operators, transporters and exporters, located in Chiang Mai, Lamphun and Bangkok. Performance of the longan supply chain members were evaluated based on four categories, namely, inbound logistics, operations, outbound logistics and supporting activities. It was found that the exporters had the highest score in every aspect of performance criteria whereas the farmers had the lowest score, especially in the outbound logistics part. The findings also showed that the major problem of this supply chain was due to oversupply of longan. It was therefore recommended that the members in the supply chain should have to manage and control the quantity of longan, so that demand and supply are balanced as well as to add value to the longan products by increasing information share between members. Marketing campaign is also important to boost longan demand. By implementing operational best practice to each supply chain member, $25 \%$ reduction in waste may be achieved.
\end{abstract}

Keywords: Longan, Supply Chain, Value Chain Analysis, SCOR Model, Waste Reduction

\section{INTRODUCTION}

Longan (Dimocarpus longan L.) is a subtropical evergreen tree species in the family of Sapindacea. The longan crops require winter chill to induce flower and normally blossom in spring, allowing fruit development in the humid and warm seasons of late spring and summer (Yang et al., 2010). Longan is an important economic fruit of Thailand because it is widely consumed domestically and abroad. In 2010, around 450,000 tons of longan were produced, where about 300,000 tons were exported as frozen, dried and canned longan, earning over US\$200 million in export value (OAE, 2011). The major trade partners were China, Taiwan and Indonesia. The quantity of domestics and export longan was limited by its highly perishable nature, short storage life and susceptibility to postharvest disease. Several preservation methods were employed to extend shelf life or add value to longan, including canning, freezing and drying (Tippayawong et al., 2008).
Longan is widely cultivated in South China Australia and Thailand. In Thailand, main longan production areas are in the Northern area where the main planting areas are in Chiang Mai and Lamphun, accounting for around 75\% of the whole yearly production, shown in Fig. 1.

For the recently several years, there are many problems that occur continually in longan production and sale. The main problem facing the longan farmers is a continual increase in production cost while the customer demand stays the same. The problem became worse when the off-seasonal longan was made available. From the production characteristics of longan whose quality depends on weather, a lack of information between farmers, a lack of distribution system and low cooperation between the related organizations in both of government and private corporation, system management to solve the problem is rather difficult. In this study, attempt was made to systematically study connection of materials in all supply chain members. 


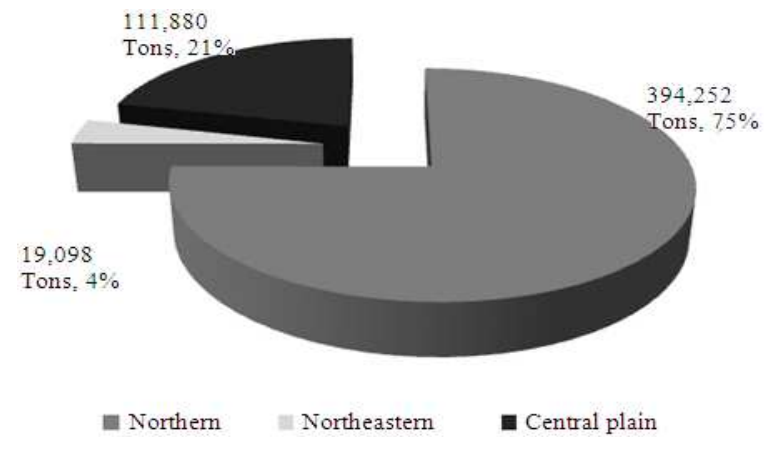

Fig. 1. Production of longan by region in 2010

This research study aims to study the characteristics of longan supply chain, identify the problem and propose ways to improve the Supply Chain Management (SCM) and logistics of longan. The outcome from this study is expected to show current situation of longan supply chain and strategy for the entrepreneurs together with government sector.

\subsection{Literature Reviews}

This study focused on the overall processes and activities in longan supply chain where SCM tools are used. Performance measurement is employed to show the strengths and weaknesses of longan supply chain so that improvement may be identified. The SCOR model and value chain analysis are used because it shows the organization in a cross function framework. The supply chain analysis using the concepts of the SCOR model and value chain could provide a capacity to increase efficiencies, business integration, responsiveness and ultimate market competitiveness.

\subsection{SCM and Performance Measurement}

SCM is an integration and management in organizations which are bringing supply chain relationships and collaboration activities to build valueadded products and services which brings the competitiveness and sustainability (Handfield and Nichols, 1999). The supply chain consists of the activities which related to response to the customer demands, not only manufacturers and transporters but including distributors, middlemen and customers. The organizations should apply SCM because it focuses on fixing the related problems with distribution network configuration, for example, production facility, distribution center, warehouse and customer, distribution strategy which are the importance part of organization process for the plow of products and information, inventory management showing how the organizations manage their finished products to deliver to their customers and the cash-flow which can be the main problem between the supply chain members (Yaibuathet et al., 2008).

The activities in the SCM can be divided into eights main activities, including (Procurement; Inventory management; Product design and new product development; Manufacturing; Order process; Transportation/distribution; Sales; Demand management; and Customer service). Supply chain performance is an overall performance measure that depends on the performance of the stages in supply chain (Lambert and Cooper, 2000). The performance of supply chain can be defined by the information or feedback on activities with respect to meeting customer expectations and strategic objectives (Chan, 2003), or the degree to how well the supply chain can fulfill end user requirement (Van der Vorst et al., 1998). According to Neely (2005), performance measurement is defined as the process of quantifying the effectiveness and efficiency of actions. With the fast change happening in the World, performance measurement plays an important role in SCM initiative and improvement (Xu et al., 2007) because it plays in setting objectives, goals, evaluating performance and determining future courses of actions. In recent years, performance measurement and indicators have acquired much attention from many researchers.

\subsection{SCOR Model}

Supply Chain Operations Reference (SCOR) model released by the Supply Chain Council in 1996 has been widely studied and used in research and industry. Researchers and practitioners have found that the SCOR model is a good reference that integrates most of the business processes of an organization in a crossfunctional framework. SCOR model is based on five distinct management processes, namely Plan, Source, Produce, Deliver and Return. These five processes form the top level of the SCOR model. Each process is further decomposed into lower levels. Level two is called configuration level where a company implements its strategy by configurations. Level three is the process elements levels to fine tune the detailed operations. Level four is the implementation level that directly deals with the practices and activities (Kocaoglu et al., 2011). Top level SCOR metrics focus on five performance attributes (Bolstorff and Rosenbaum, 2007), as follows:

- Reliability: the performance related to the delivery, i.e., whether the correct product (according to specifications) is delivered to the correct place, in the correct quantity, at the correct time, with the correct documentation and to the right customer

- Responsiveness: the speed at which a supply chain provides the products to customers

- Flexibility: the agility of a supply chain to respond to market changes in demand in order to gain or maintain its competitive advantage 
- Cost: all the costs related to the operation of a supply chain

\subsection{Asset Management Efficiency}

The efficiency of an organization in managing its resources to meet demand. This includes the management of all the resources: fixed and working capital.

The SCOR model offers the companies with a feature which shows how the processes from start to end can be improved. It also has the standard process definitions and metrics that suitable for all types of business conditions and operations (Bolstorff, 2002; 2003). When compared with ISO 9000, the benefit of SCOR model is to enable companies to manage operational and financial performance, while the ISO 9000 scope does not consider about accounting and finance functions (Reichardt and Nichols, 2003). Previous studies indicated that the SCOR model can be modified to be suitable with different industry context for supply chain performance measurement proposed. Hwang et al. (2008) proposed a network-topology structure of Cycle Quality Chain Operations Reference (CQCOR) based on SCOR model. This newly-developed model has been employed in evaluating performance of sourcing process in Taiwan's TFT-LCD industry. Moreover, Lai et al. (2002) combined the SCOR model with other performance measurement models to construct measurement instrument for evaluating supply chain performance in transportation business. The implementation of SCOR model has also been found in agro-product industry. The benchmarking concept of SCOR model was highlighted to generate a framework for measuring logistics performance in Argentinean wine industry (Garcia et al., 2012).

Although several implementations of the SCOR model are detected in different industry contexts, their obvious implementation in agro-product has been rather limited. Therefore, the analysis of longan supply chain with the concept of SCOR model is proposed in this research study.

\subsection{Value Chain Analysis}

The value chain is a business model that enables the organizing of operations around the value adding activities that result in a better service or product. The proposed model thus benefits from a sound business principle for organizing activities (Porter, 1985). Value chain analysis describes the activities within and around an organization and relates them to an analysis of the competitive strength of the organization. Therefore, it evaluates which value each particular activity adds to the organizations products or services. This idea was built upon the insight that an organization is more than a random compilation of machinery, equipment, people and money. Only if these things are arranged into systems and systematic activates, it will become possible to produce something for which customers are willing to pay a price. Mentzer et al. (2001) argues that the ability to perform particular activities and to manage the linkages between these activities is a source of competitive advantage. The goal of these activities is to offer the customer a level of value that exceeds the cost of the activities, thereby resulting in a profit margin. The primary value chain activities are (Rieple and Singh, 2010):

- Inbound logistics: the receiving and warehousing of raw materials and their distribution to manufacturing as they are required

- Operations: The processes of transforming inputs into finished products and services

- Outbound logistics: The warehousing and distribution of finished goods

- Marketing and sales: The identification of customer needs and the generation of sales

- Service: The support of customers after the products and services are sold to them

These primary activities are supported by:

- The infrastructure of the firm: Organizational structure, control systems, company culture

- Human resource management: Employee recruiting, hiring, training, development and compensation

- Technology development: Technologies to support value-creating activities

- Procurement: Purchasing inputs such as materials, supplies and equipment

The value chain analysis has been implemented in various agro-product sectors such as organic cotton, sugar or wine industry (Higgins et al., 2007; Ponte and Ewert, 2009; Rieple and Singh, 2010). Different activities in value chain of Indian organic cotton were analyzed to realize where and how value is added in each stage of production. Afterward, the opportunity for value addition which is currently missed is pointed out. From the study, the inefficiency or ineffectiveness activities are identified thorough a systematic categorization then the improvement is suggested for better value creation in the processes within the chain (Rieple and Singh, 2010). Value chain research in sugar industry is conducted in various aspects. Higgins et al. (2006) categorizes sugar value chain research into two entities, which are logistical and non-logistical opportunities. The development and application of model to improve the combined scheduling of harvesting and transport activities to achieve desire supply of cane to the mill at the least cost is one of the notable logistical opportunities. These included those by Higgins et al. (2004) for the Australian sugar industry, Yosnual and Subsomboon (2004) for Indonesia and Perry and Wynne (2004) for South Africa. In the context of non-logistical opportunities, many 
researches focused on implementing information technologies for better value chain management (Ramingwong et al., 2011). Crane and Flemming (2003) indicated that the use of information technology to improve chain decision making has considerable potential in sugar industry around the world. In South African wine industry, the concept of Global Value Chain (GVC) has been employed in order to "upgrade" this industry level. However, upgrading South African wine is more complex than just improved product quality, better process or some functional upgrading. Such improvements have co-existed with demand for higher volume of basic quality of wines and increase demand of bulk delivery, shorter lead times and higher flexibility in delivering to buyer specifications (Ponte and Ewert, 2009).

Although the value chain researches in agroproducts are extensive, their applications to longan chains have been rare. Similar value chain analysis techniques in previous researches could be modified to implement to Thailand longan industry.

\section{MATERIALS AND METHODS}

The data collection process involved supply chain members of longan production, mainly in the Northern of Thailand. Those included were farmers, middleman, driers, transporters and exporters. Initially, the value chain of longan supply chain members was analyzed. Then, the performance evaluation was conducted on both main and supporting activities of each member. They were categorized into four perspectives, namely, inbound logistics, operations, outbound logistics and supporting activities. At this stage, the in-depth interview was conducted with 73 members located in Chiang Mai, Lamphun and Bangkok. Some parts of interview results were outlined into value chain model. Figure 2 shows the overall processes and members in the longan supply chain. The main path for longan distributions to final consumer is thought to be via collectors in the provincial level, local level or cooperative. After collection, longan is sold to the wholesale market and distributes to the final consumer afterwards. For exporting longan, it has to be broiled with sulfur dioxide for self life extension, prior to export to modern trade.

The longan value chain model focuses on the activities which include material procurement, production process transportation and customer service. This model emphasizes increased competitive ability by analyzing and increasing value from each activity. Value chain model shows connection of activities which increase value for the supply chain in both external and internal processes in competition.

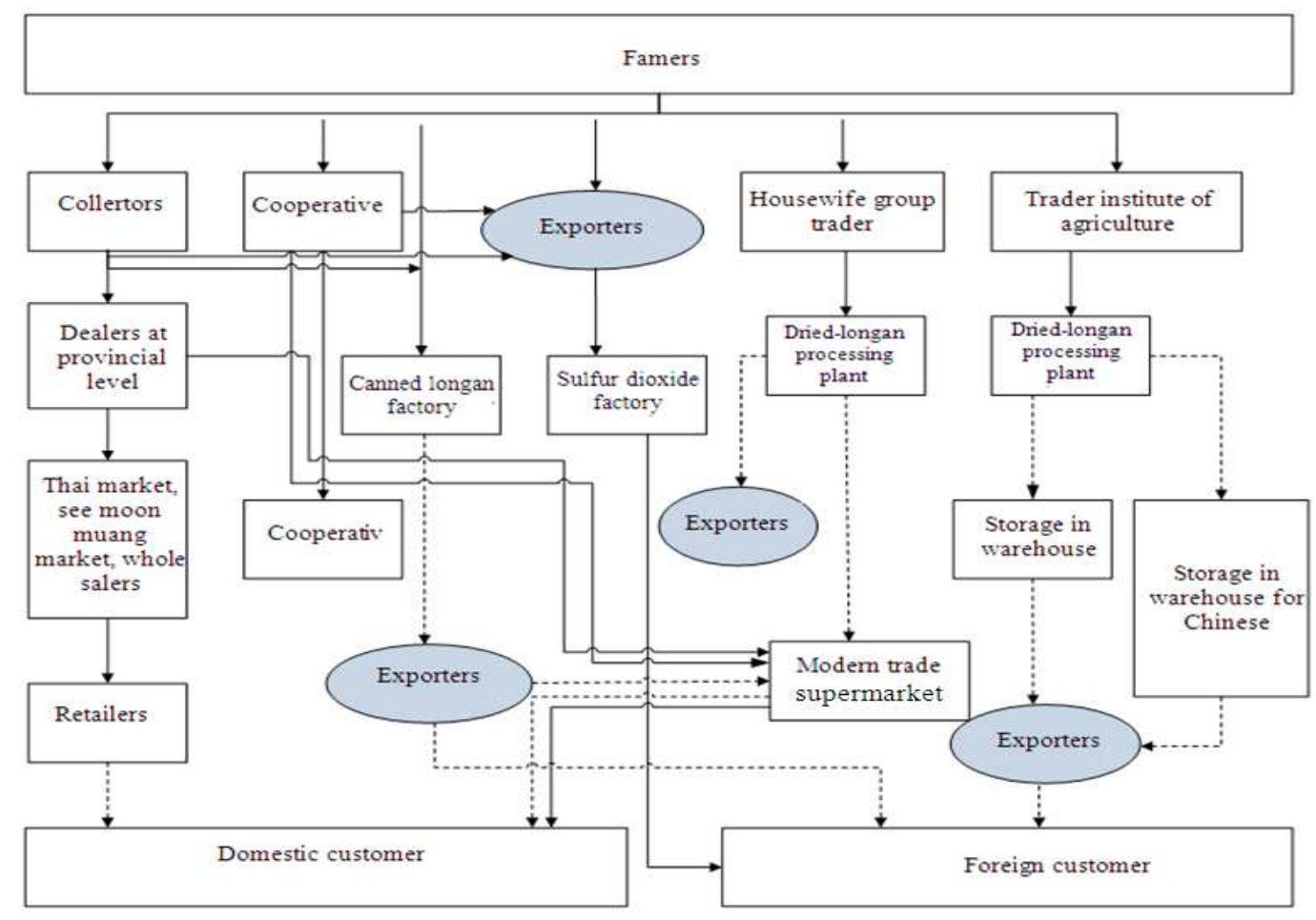

Fig. 2. Longan value chain model 


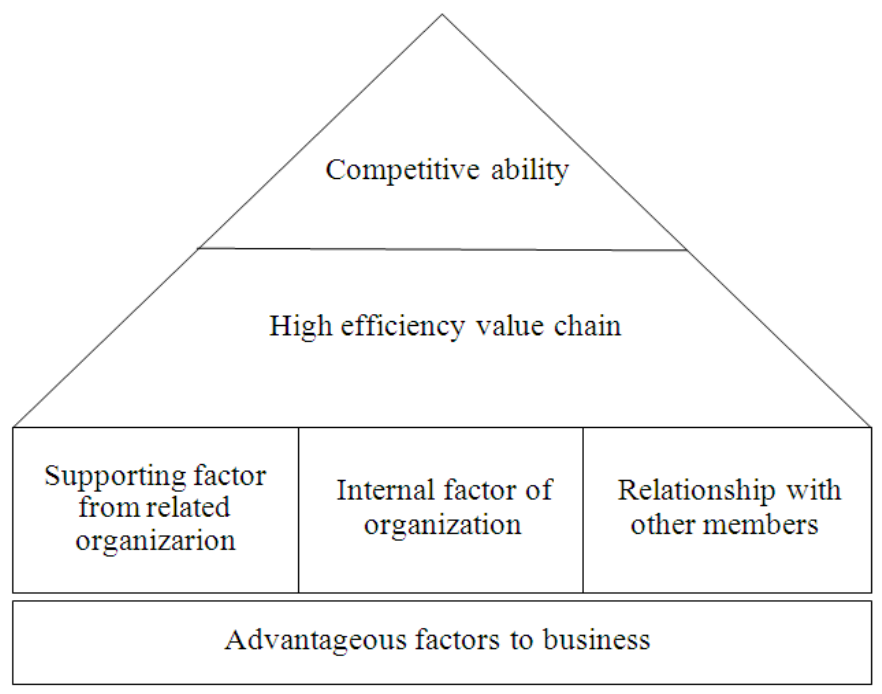

Fig. 3. Competitive development based on value chain concept

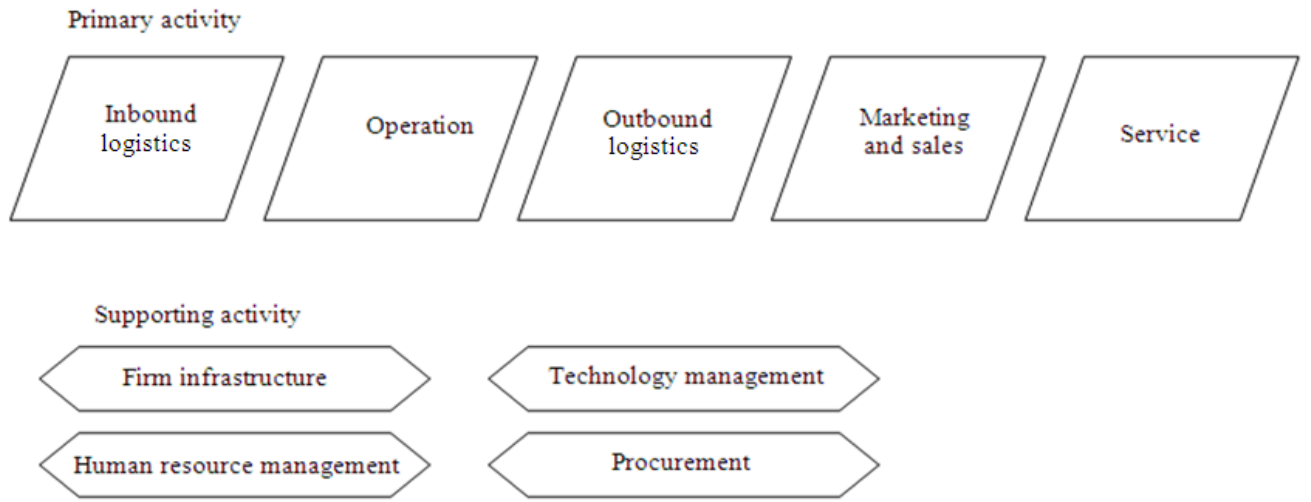

Fig. 4. Value chain of longan

Development of competition is based on applying the concept of the value chain. The basic factors are supporting factors from related organization, internal factor of organization, relationship with other members, shown in Fig. 3. The main purpose for this research was to develop and strengthen the supply chain that is able to respond quickly to customer needs. In the current operation, the members in supply chain work independently, having no combined strategy between them.

In the performance measurement, the activities in the longan supply chain were considered. In this part, the activities were classified into two parts; primary activity and supporting activity (Fig. 4). The primary activity represents activity which affects the value in the product or service to consumer directly, consisting of five main activities:
- Inbound logistics, this activity represent the preparation material before production, for example receiving material from suppliers or material storage

- Operation, it is an activity which related to production processes, for example processing product or packaging

- Outbound logistics. After production process, next step is transportation to other members in supply chain which are wholesalers, retailers and final consumer

- Marketing and sales, this part is about identify and analyze the consumer requirement and transfer into the information to production plan or production mix and publicize product or service information.

- Service, this activity happens after trading, for example after-sales service 
Table 1. The KPIs for performance measurement of collectors

\begin{tabular}{|c|c|}
\hline Inbound logistics & $\begin{array}{l}\text {-Clearly identify the customers and indentify service and products by customers } \\
\text {-Information sharing with customers and effective channels for sharing information with them } \\
\text {-Satisfaction measurement and application } \\
\text {-Customer complaints management } \\
\text {-Effective communication in requirement and complaints from customers to operators } \\
\text {-Identify the different, advantage and disadvantage with the competitor for customer fulfillment } \\
\text {-Reasonable price which can fulfill the requirement and compete with others }\end{array}$ \\
\hline Supplier management & $\begin{array}{l}\text {-Fresh longan providing } \\
\text {-Quality measurement of longan } \\
\text {-Storage } \\
\text {-Longan procurement } \\
\text {-Supplier assessment } \\
\text {-Control }\end{array}$ \\
\hline Operation & $\begin{array}{l}\text {-Production quantity } \\
\text {-Production time } \\
\text {-Processing } \\
\text {-Quality standard } \\
\text {-Packaging } \\
\text {-Maintenance } \\
\text {-Networking }\end{array}$ \\
\hline Outbound logistics & $\begin{array}{l}\text {-Marketing } \\
\text {-Deliver pattern } \\
\text {-Type of vehicle } \\
\text {-Delivery provider assessment } \\
\text {-Quantity of delivered product }\end{array}$ \\
\hline Supporting factors & $\begin{array}{l}\text {-There is effective systematic in quality management } \\
\text {-There is effective systematic in financial management } \\
\text { - There is systematic staff training } \\
\text { - There is government or private funding sources for systematic support. } \\
\text {-There is other government or private sector organization to support the physical infrastructure. } \\
\text {-There is other government or private sector organization to support social capital. } \\
\text {-There is other government or private sector organization to worker support }\end{array}$ \\
\hline
\end{tabular}

The members in the supply chain were divided into five main groups The KPIs for each member are different, depending on their operations. The examples of KPIs for collectors are shown in the Table 1.

\section{RESULTS}

\subsection{Performance Measurement}

For the measuring KPIs, different questionnaires and interviews were used according to grouping of members in the supply chain. There are five levels of KPIs in performance measurement. The fifth level with 5 point is the full mark. Identifications of each level are shown in Table 2. The measurement results of 5 main groups of longan supply chain members are summarized. Points were normalized by the best practice for each activity in the longan value chain model; hence results can be compared between different organizations.

\subsection{Farmers}

The farmers' group measurement result is shown in Fig. 5. Four main activities; inbound logistics, operation, outbound logistics and supporting were measured. The results show that the farmers get the best point in inbound logistics because of their experience in longan cultivation. This is because Thailand is agrarian country, so characteristics, behavior and basis in planting are suitable with environment. The reasons why other activities receive lower points than inbound logistics are that most farmers choose to ignore communication. They are not familiar with modern communication technology.

\subsection{Collectors}

Also shown in Fig. 5, the overall performance of collectors shows that most collectors manage the same level, in term of operation. This is because the operations of the collectors are simply to collect and inspect longan from the farmers. Farmers operation is more complicated because it consists of many procedures for planting. The collectors operation is rather short per year. The highest point obtained is inbound logistics where the main operation of collectors is communication with other member in longan supply chain such as farmers or processing plant. Effective transportation is the main KPIs of collectors which related directly to inbound and outbound logistics. If we consider the result in the term of operation, the average point is lowest. Suitable management was lacking in term of finance and place. Information sharing is non-existent. 
Table 2. Measurement level

\begin{tabular}{ll}
\hline Level & Identification \\
1 & Bad: no practice or pattern of practice is bad or working concept has bias which affects work or improvement \\
2 & Fair: practically no practice or no pattern of practice or working concept has bias which affects work or improvement \\
3 & Moderate: some practice in the moderate level, no express an opinion \\
4 & Good: usually practice and contain good guideline for working \\
5 & Very good: good practice, good working concept and always practice \\
\hline
\end{tabular}

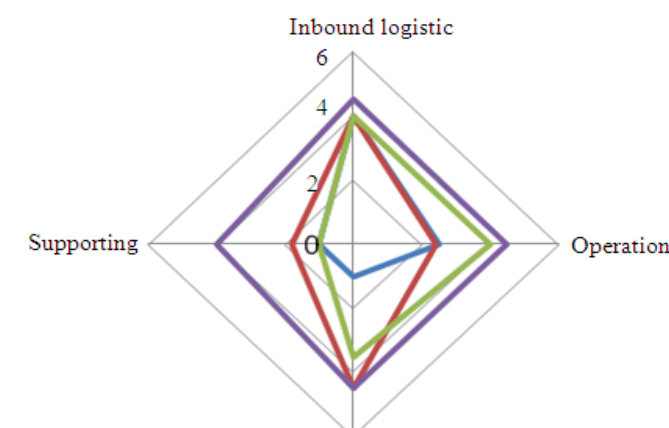

Outbound logistic
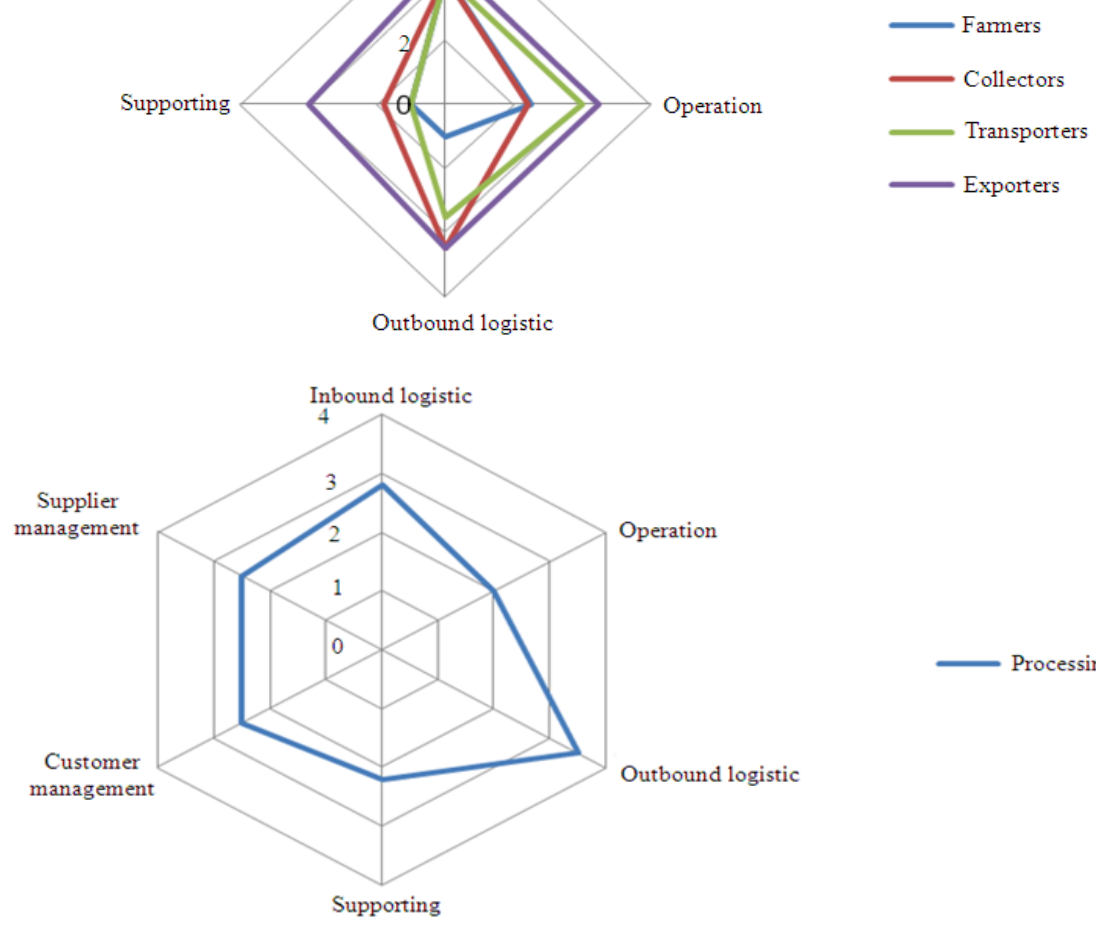

Fig. 5. The performance result of longan supply chain members

\subsection{Processing Plants}

The processing plants can be measured by six main activities; inbound logistics, operation, outbound logistics, customer management, supplier management and supporting factors. It was found that the processing plants are best in outbound logistics, followed by inbound logistics while the worst one is operation. This may be due to the variety of procedures in processing plants. The standard practice is not in the same direction and the storage is different for different products. These factors affect quality, time and cost. For the outbound logistics, it was found to be in good level because certain standards from the customer requirement, for example package and packaging time are followed strictly.

\subsection{Transporters}

The transporters are related to four main activities which are outbound logistics, operation, supporting and marketing and sales. The inbound logistics activity cannot be measured because the activities cannot be separated from operation activities clearly. In term of operation and inbound logistics, the sample organizations were found to manage well. They have to provide effective transportation as good as they can. The other activities appeared to have similar level to other supply chain members. The organizations still ignore applying suitable management and information sharing.

\subsection{Exporters}

Overall results show that the sample organizations obtain similar point for four activities. This is because the 
export procedures are not complicated and they have their standard procedures to follow according to trading rules. Accurate communication is the first priority since the operations of exporters are related directly to inbound and outbound logistics. There is no step in processing product.

\section{DISCUSSION}

The measurement is concluded in Fig. 6. The problems which occurred in the longan supply Chain were from members and between members of the supply chain. Most members have the same problem which is the lack of management both in production knowledge and labor. For example, production knowledge in farmers' part and processing knowledge in collectors' part were not shared. But, in the exporters' part, the main problem is about the export procedure to destination countries such as importing procedures and Non-Tariff Barriers (NTB). The main problem between the members is no information sharing which led to many other problems.

\subsection{Improvement Options}

\subsection{Loss reduction in the Longan Supply Chain}

Loss from the supply chain can be assorted in many types, depending on the characteristics of organizations. All losses affect operation cost. If the organizations are aware of loss reduction in both of time and cost term, the operation cost will be decreased. This study will present some examples of loss reduction in exporting fresh longan. The loss from exporting longan occurs in many processes, but the main loss is in the harvesting process. The loss and loss reduction are shown in Fig. 7. It indicates that the result relies on most of the maintenance procedures. As long as the farmers are capable of keeping up the improvement of the maintenance regulations, the products will be high in quality. The improvement can proceed by collecting data from those who have experienced in the most minimized damage. Procedures such as well-managed fertilizing, regularly performed soil inspection is effective. When the fruition of longans is about 50-60 longans per bud, the appropriate equipment to harvest must be used. The personnel who are experienced, well trained in size qualifying and acid check for the unqualified longans to assure that there is no acid are also effective to the procedures. On the other hand, the efficient communication between the clients and the collectors is also necessary in order to improve the farmer's potential to the client's expectation. The collectors should operate with qualified personnel that can point out experienced candidates, keep the knowledge of longan qualification bequeathing and also can create motivation for personnel to follow procedures. General ways to improve the efficiency of longan supply chain management for members in the supply chain and the government sector may be divided into three main sectors, as follows:
- Operation and management

- Marketing

- Product

By implementing supply chain member's best practice, improved harvesting procedure could reduce around $30 \%$ of waste cost. Moreover, $20 \%$ of cost was also trimmed down from better grading process. The main problem is the over-supply of longan, so the members in the supply chain have to manage and control the quantity of longan as well as to add value to the longan products. Additionally, marketing campaign is also important to increase and support longan demand.

\subsection{Improvement in Operation and Management}

Long term operation planning should be carried out. The farmers must succeed in quality production. The plant management should be provided because it can help in product control. The product should be supplied all year round, along with promoting the off-seasonal longan plantation. Advantage and methodology of offseasonal longan should be promoted. Off-seasonal longan can help decreasing financial risk. Cultivation of alternative crops for example, home-grown vegetable or plant for animal feed should also be supported. The famers will earn extra income throughout the years.

\subsection{Improvement in Marketing}

Fresh longan consumption should be promoted domestically. At present, fresh longan consumption is quite low because of the Thai belief that fresh longan is a cause of apthous ulcer. Therefore, strategy for fresh longan promotion should be generated and implemented. This promotion will focus on the advantage of longan and enlarge domestic market. The government offices can take active role in this support. Furthermore, the government should also concern about foreign market. Nowadays, the main foreign market is China with only $10 \%$ export to other countries in Asia. The government may act as middle men to expand fruit market to other countries, possibly to Europe, Japan, India and Indonesia.

\subsection{Product improvement}

Low longan selling price is from over-supply of longan. Strengths and weaknesses should be evaluated to identify ways to increase value of longan. Processing is one way to increase the value and quality to consumer. It can also produce variety of products and prolong self-life. From many studies on fruit processing, there are many useful methods that can be utilized. This is the great opportunity to expand market of longan which can increase demand and value of longan. 
Apichat Sopadang et al. / American Journal of Agricultural and Biological Sciences 7 (3) (2012) 301-311

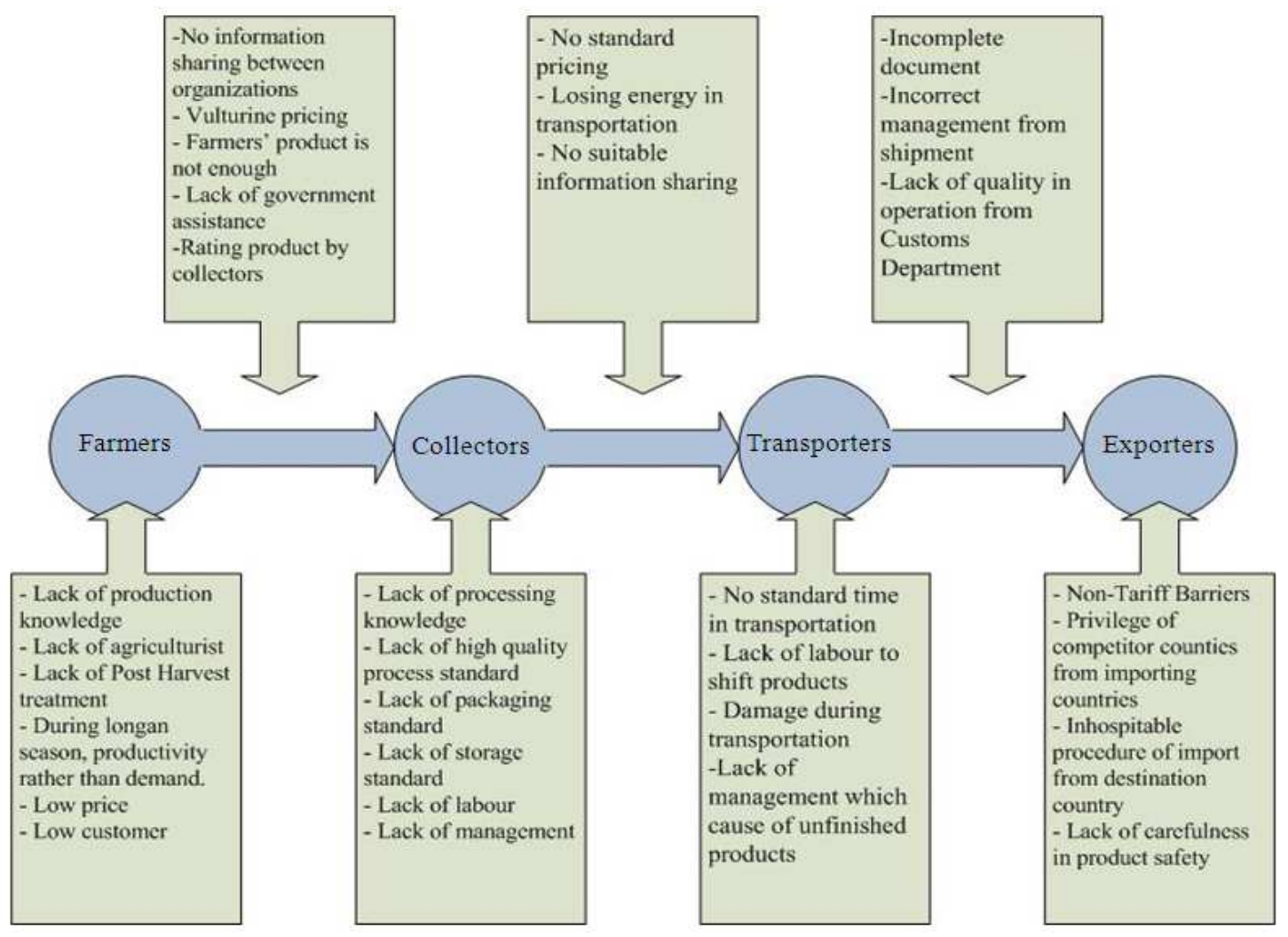

Fig. 6. Problem in longan supply chain

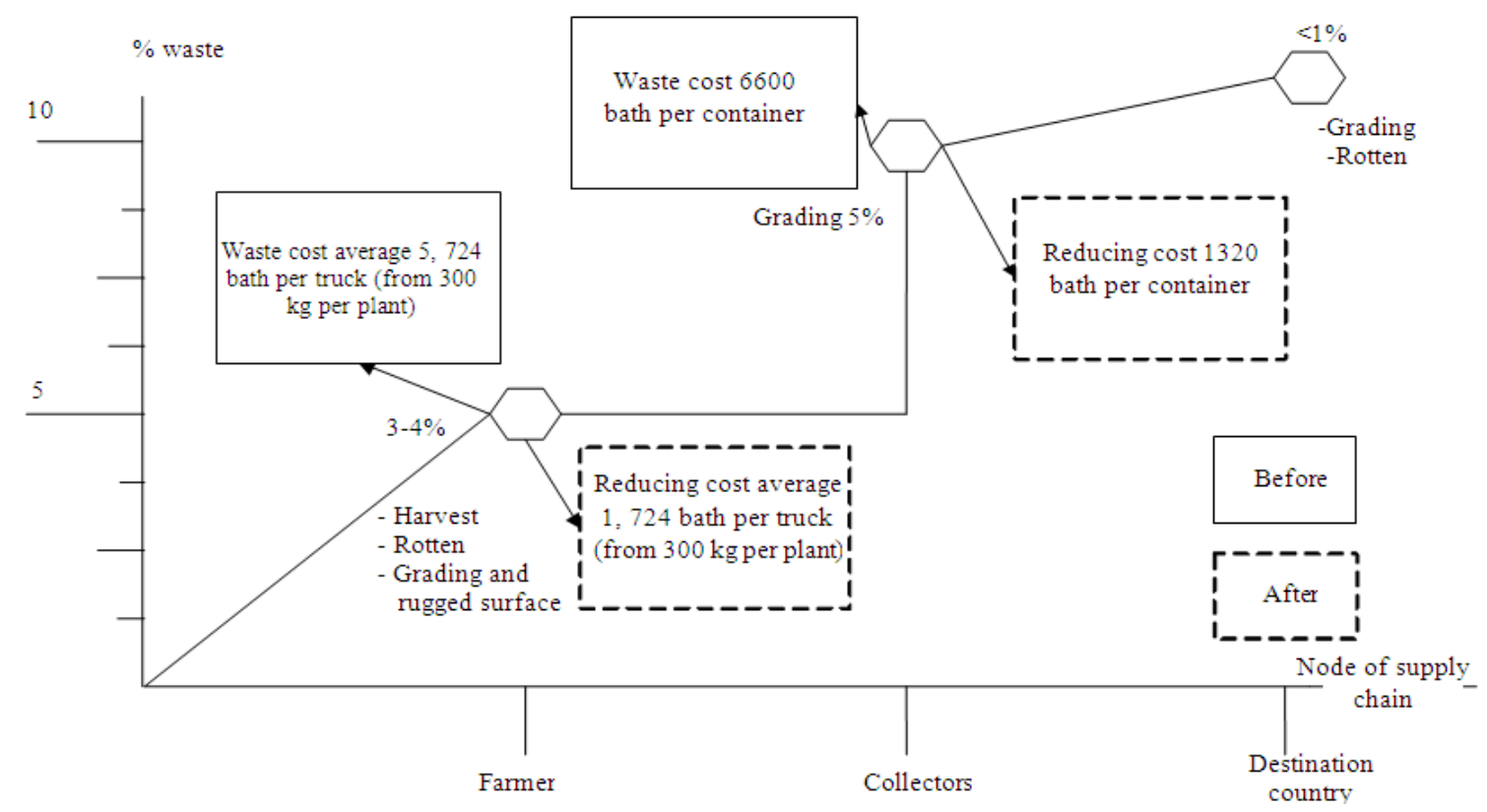

Fig. 7. Node of supply chain of fresh export longan 


\section{CONCLUSION}

In this study, current structure of the longan supply chain management has been studied. The problems encountered by the supply chain members were identified. Efficiency according to value chain model has been evaluated. Improvement options to increase efficiency of longan supply chain management have been proposed and discussed. Improvements in three sectors are needed. They are cultivation of off-seasonal longan, creation of a new market, adding value of longan and creating variety of longan products. Further research is still needed to increase efficiency of longan supply chain management, such as application of communication technology to enable information sharing or knowledge in off-seasonal planting. This research may contribute greatly to the study of value chain management of other economics crops for better value creation.

\section{ACKNOWLEDGEMENT}

This study is financially supported by the Commission on Higher Education's National Research University Project.

\section{REFERENCES}

Bolstorff, P., 2002. How does SCOR Measure up. Supply Chain Technol.

Bolstorff, P., 2003. Measuring the Impact of supply Chain Performance. Logistics Today.

Bolstorff, P. and R.G. Rosenbaum, 2007. Supply Chain Excellence: A Handbook for Dramatic Improvement Using the Scor Model. 1st Edn., AMACOM Div American Mgmt Assn, New York, ISBN-10: 0814409261, pp: 277.

Chan, F.T.S., 2003. Performance measurement in a supply Chain. Int. J. Adv. Manufacturing Technol., 21: 534-548.

Crane, J.A. and G.F. Flemming, $2003 . \quad$ Improving information flows in the sugar industry supply chain: the Mackay sugar web portal. Int. Sugar J., 105: 515-519.

Garcia, F.A., G.M. Martin, C. Mauricio, M. Laure and Q. F. Raymundo, 2012. A framework for measuring logistics performance in the wine industry. Int. J. Prod. Econo., 135: 284-298. DOI: 10.1016/ j.ijpe.2011.08.003
Handfield, R.B. and E.L. Nichols, 1999. Introduction to Supply Chain Management. 1st Edn., Prentice Hall, New Jersey, ISBN-10: 0136216161, pp: 183.

Higgins, A., P. Thorburn, A. Archer and E. Jakku, 2007. Opportunities for value chain research in sugar industries. Agric. Syst., 94: 611-621. DOI: 10.1016/j.agsy.2007.02.011

Higgins, A., G. Beashel and A. Harrison, 2006. Scheduling of brand production and shipping within a sugar supply chain. J. Operational Res. Soc., 57: 490-498. DOI: 10.1057/palgrave.jors.2602025

Hwang, Y.D., Y.C. Lin and J. Lyu Jr., 2008. The performance evaluation of SCOR sourcing processthe case study of Taiwan's TFT-LCD industry. Int. J. Prod. Econ., 115: 411-423. DOI: 10.1016/j.ijpe.2007.09.014

Higgins, J.D., S.J. Armstrong, F.C.H. Franklin and G.H. Jones, 2004. The Arabidopsis MutS homolog AtMSH4 functions at an early step in recombination: Evidence for two classes of recombination in Arabidopsis. Genes Dev., 18: 2557-2570. DOI: $10.1101 / \mathrm{gad} .317504$

Kocaoglu, B., B. Gulsun and M. Tanya, 2011. A SCOR based approach for measuring a benchmarkable supply chain performance. J. Intel. Manufact., DOI: 10.1007/s10845-011-0547-z

Lai, K. H., E.W.T. Ngai and T.C.E. Cheng, 2002. Measures for evaluating supply chain performance in transport logistics. Trans. Res. Part E: Log. Trans. Rev., 38: 439456. DOI: $10.1016 / \mathrm{S} 1366-5545(02) 00019-4$

Lambert, D.M. and M.C. Cooper, 2000. Issues in supply chain management. Indus. Marketing Manag., 29: 65-83. DOI: 10.1016/S0019-8501(99)00113-3

Mentzer, J.T., W. Dewitt and J. S. Keebler, 2001. Defining supply chain management. J. Bus. Logistics, 22: 1-25. DOI: 10.1002/j.21581592.2001.tb00001.x

Neely, A., 2005. The evolution of performance measurement research: Developments in the last decade and a research agenda for the next. Int. J. Operations Prod. Manag., 25: 1264-1277. DOI: $10.1108 / 01443570510633648$

OAE, 2011. Import-Export Statistics. Office of Agriculture Economics.

Perry, I.W. and A.T. Wynne, 2004. The sugar logistic improvement programmed (slip): an initiative to improve supply chain efficiencies in the South African sugar industry. Int. Sugar J. 
Ponte, S. and J. Ewert, 2009. Which way is "Up" in upgrading? trajectories of change in the value chain for south african wine. World Dev., 37: 1637-1650. DOI: 10.1016/j.worlddev.2009.03.008

Porter, M.E., 1985. Competitive Advantage: Creating and Sustaining Superior Performance. 1st Edn., Free Press, New York, ISBN-10: 0029250900, pp: 557.

Ramingwong, S., K.Y. Tippayawong and A. Sopadang, 2011. On the development of i-community to improve production of off-season longan. Aus. J. Basic Applied Sci., 5: 649-654.

Rieple, A. and R. Singh, 2010. A value chain analysis of the organic cotton industry: The case of UK retailers and Indian suppliers. Ecol. Econ., 69: 2292-2302. DOI: $10.1016 /$ j.ecolecon.2010.06.025

Reichardt, E. and L.J. Nichols, 2003. SCOR your ISO certification. Quality, 42: 44-47.

Tippayawong, N., C.Tantakitti and S. Thavornun, 2008. Energy efficiency improvements in longan drying practice. Energy, 33: 1137-1143.

Van der Vorst, J.G.A.J., A.J.M. Beulens, W.D. Wit and P.V. Beek, 1998. supply chain management in food chains: Improving performance by reducing uncertainty. International Transactions in Operational Research, 5: 487-499. DOI: 10.1111/j.1475-3995.1998.tb00131.x
Xu, L.X.X., B. Ma and R. Lim, 2007. AHP based supply chain performance measurement system. Proceedings of the 12th IEEE International Conference on Emerging Technologies and Factory Automation, Sept. 25-28, IEEE Xplore Press, Singapore, pp: 1308-1315. DOI: 10.1109/EFTA.2007.4416932

Yang, W.H., S.C. Deng, X.C. Zhu, H.C. Wang and H. $\mathrm{Wu}, 2010$. Developmental problems in over-winter off-season longan fruit. II: Development of pericarp structure. Scientia Horticulturae, 126: 359-365. DOI: $10.1016 /$ j.scienta.2010.07.029

Yosnual, J. and S. Supsomboon, 2004. An integer programming for sugarcane factory supply allocation. Proceedings of the 5th Asia Pacific Industrial Engineering and Management Systems Conference, (APIEMSC' 04), Published on CDROM. Australia.

Yaibuathet, K., T. Enkawa and S. Suzuki, 2008. Influences of institutional environment toward the development of supply chain management. Int. J. Produ. Econ., 115: 262-271. DOI: 10.1016/j.ijpe.2008.02.018 